\title{
Kronik Böbrek Yetmezlikli Çocuk Sahibi Olan Ebeveynlerin Aşılar Hakkındaki Bilgi Düzeyi
}

\section{The Knowledge Level of Parents with Chronic Renal Failure About Vaccines}

\author{
Esra Yazarlı ${ }^{1}$, Aysel Taktak ${ }^{2}$ (D), Mehtap ÇelakıI ${ }^{3}$ (D)
}

\author{
${ }^{1}$ Hatay Mustafa Kemal Üniversitesi, Tıp Fakültesi, Çocuk Sağığı ve Hastalıkları Anabilim Dalı, Hatay, Türkiye \\ ${ }^{2}$ Hatay Mustafa Kemal Üniversitesi, Tıp Fakültesi, Çocuk Nefroloji Anabilim Dalı, Hatay, Türkiye \\ ${ }^{3}$ Hatay Devlet Hastanesi, Çocuk Nefroloji Kliniği, Hatay, Türkiye
}

ORCID ID: E.Y. 0000-0002-2347-8168; A.T. 0000-0001-7724-9160; M.Ç. 0000-0002-5354-1455

Citation/Attf: Yazarli E, Taktak A, Celakil M. Kronik böbrek yetmezlikli çocuk sahibi olan ebeveynlerin aşılar hakkındaki bilgi düzeyi. Çocuk Dergisi - Journal of Child 2021;21(2):161-165. https://doi.org/10.26650/jchild.2021.874420

Öz

Amaç: Kronik böbrek yetersizliği (KBY) tanılı çocuklarda yüksek enfeksiyon riski nedeniyle aşılar önemli bir koruyucu sağlık hizmetidir. Bu çalışmada, KBY tanılı çocuklarda aşılanma oranı ve bu oranı etkileyen faktörler incelendi.

Yöntem: Tanımlayıcı kesitsel tipteki çalışmamıza Kasım 2020-Ocak 2021 tarihleri arasında, KBY tanısı ile takipli 0-18 yaş arası 81 hastanın ebeveynleri alındı. Ebeveynlere 29 sorudan oluşan anket formu yüz yüze görüşme tekniği ile uygulandı. Ebevenylerin demografik özellikleri, hastaların ulusal aşılama takviminde olan aşılarla aşılanma durumu ve ulusal aşı takviminde olmayan meningokok, influenza ve human papilloma virüs aşısı ile aşılanma durumları kaydedildi. Ulusal aşılama takvimine çocuğun aşılanma zamanından sonra eklenen aşıların tamamlanıp tamamlanmadığı ve aşı yaptırmayan ailelere aşı yaptırmama nedenleri soruldu.

Bulgu: Hastaların ulusal aşı takvimine göre aşılanma oranının \%85,2 ( $n=69$ ) olduğu ve ebeveynlerin \%75,3'ünün ( $n=61$ ) aşı eğitimi aldığı görüldü. Aşı eğitimi alan ebeveynlerin çocuklarının ulusal aşı takvimindeki aşılarla aşılanma oranı eğitim almayan ebeveynlerin çocuklarına göre istatistiksel olarak yüksek saptandı $(p<0,001)$. Aylık geliri yüksek olan hastalarda influenza, meningokok, hepatit A, suçiçeği aşılanma oranı aylık geliri düşük olan hastalara göre istatistiksel olarak yüksek saptandı (sırasıyla $p<0,001 ; p<0,001 ; p=0,010 ; p=0,029$ ). En az bilinen ve yaptırılan aşının human papilloma virüs aşısı olduğu görüldü.

Sonuç: KBY tanılı hastaların aşılanma oranının düşük olduğu saptandı. Ulusal aşı takvimine hastanın aşılanma zamanından sonra eklenen ya da ulusal aşı takviminde olmayan aşılar hakkında ailelerin bilgi düzeyinin çok düşük olduğu görüldü. Ebeveynlere yönelik aşı eğitimlerinin arttırılması ve hastaların aşılanma durumunun daha dikkatli takip edilmesi gerekmektedir.

Anahtar Kelimeler: Aşılar, çocuk, kronik böbrek yetersizliği

\section{ABSTRACT}

Objective: Vaccines are an important preventive health service due to the high risk of infection in children with chronic kidney failure (CKF). This study aimed to examine the vaccination rate in children with CKF and affecting factors.

Methods: Parents of 81 patients who were followed up with a diagnosis of CKF between the ages of 0-18 were included. The questionnaire form, consisting of 29 questions was applied to the parents using a face-to-face interview technique. The parents' demographic characteristics, the vaccination status of the patients with the vaccines in the national vaccination schedule, and vaccination status with meningococcal, influenza, and human papilloma virus that are not in the national vaccination schedule were recorded.

Results: It was observed that $85.2 \%$ of the patients $(n=69)$ had complete vaccinations in the national vaccination schedule, and $75.3 \%(n=61)$ of the parents received vaccination training. The immunization rate with vaccines in the national vaccination schedule of the children of parents who received vaccination training was statistically significantly higher than the children of parents who did not receive training $(p<0.001)$. It was seen to be the least known human papilloma vaccine.

Conclusion: It was found that the vaccination rate of patients with CKF was low. Vaccination training for parents should be increased, and their vaccination status should be followed more carefully.

Keywords: Children, chronic renal failure, vaccination

Corresponding Author/Sorumlu Yazar: Esra Yazarlı E-mail: esrayazarli@gmail.com

Başvuru/Submitted: 04.02.2021 • Revizyon Talebi/Revision Requested: 30.03.2021 • Son Revizyon/Last Revision Received: $13.04 .2021 \bullet$ Kabul/Accepted: 13.07.2021 


\section{Giriş̧}

Aşılar, insan sağlığını korumak ve bulaşıcı hastalıkları önlemek için en etkili, güvenli ve maliyeti en düşük koruyucu sağlık hizmetlerinden biridir (1). Ülkemizde 1981 yılında Sağlık Bakanlığı tarafindan "Genişletilmiş Bağışıklama Programı" başlatılmıştır. Ayrıca aşılama ile ilgili birçok kurul ve çalıştay yürütülmektedir. Ulusal aşı takvimi kapsamı yeni aşılar eklenerek genişletilmekte ve çocuklarda aşılama oranı her geçen yıl artırılmaktadır (2). T.C Sağlık Bakanlığı Ulusal Çocukluk Dönemi Aşılama Takvimi 2020'de hepatit B, tüberküloz, difteri, boğmaca, tetanoz, pnömokok, H. İnfluenza tip b, poliyomiyelit, kızamık, kızamıkçık, kabakulak, suçiçeği, hepatit A enfeksiyonlarına karşı aşılar bulunmaktadır. Ülkemizde ulusal aşı takviminde bulunmayan meningokok, influenza ve human papilloma virüs (HPV) aşılarının yapılması da önerilmektedir. Özellikle kronik hastalıkları olan ve immünsüpresif kişilerde aşılanma son derece önemlidir. Kronik böbrek yetersizliği (KBY) hastalarında enfeksiyonlar en sık ölüm nedenlerindendir (3). İmmünsüpresif ilaç tedavileri, üremik toksinler, diyaliz tedavisi, malnütrisyon ve aşı sonrası düşük antikor yanıt KBY hastalarının enfeksiyonlara daha duyarlı olmasının başlıca nedenleridir (4-6). Bu bakımdan KBY hastalarında ulusal aşı takvimine ek olarak aşı takviminde olmayan aşıların da tamamlanması önerilmektedir. Ayrıca bu hastalar böbrek nakli için adaydır ve nakil öncesi özellikle canlı aşılarının tamamlanması gerekmektedir (7). İmmünsüpresyon ve/veya tekrarlayan hastanede yatış gerektiren durumlar rutin aşılama programında eksiklikler oluşturmaktadır. Aşılama oranının başarılı olabilmesi için ulusal aşılama politikalarının yanında ailelerin aşılar hakkındaki bilgi ve düşünceleri de önemlidir. Yapılan çalışmalarda ailelerin gelir düzeyi, eğitim durumları ve aşılar hakkındaki bilgi düzeylerinin aşılama oranlarına etkileri gösterilmiştir (8-10). Bu çalışmanın amacı bölgemizde KBY hastalarında aşılanma oranları ve bu orana etki eden faktörlerin belirlenmesidir.

\section{GEREÇ VE YÖNTEM}

Çalışmamıza Çocuk Nefroloji ve Çocuk Sağlığı ve Hastalıkları polikliniğine Kasım 2020-Ocak 2021 tarihleri arasında başvuran KBY tanısı ile takipli 0-18 yaş arası 81 hastanın ebeveynleri alındı. KBY tanısı, The Kidney Disease Improving Global Outcomes (KDIGO) 2012 Clinical Practice Guideline'da tanımlanmış olan tanım, tanı ve tedavi yaklaşım önerileri temel alınarak konuldu (11).

Katılımcılara araştırmacılar tarafindan ilgili literatür bilgileri ve daha önce yapılan benzer çalışmalara dayanarak hazırlanan kapalı uçlu iki seçenekli ve çok seçenekli 29 sorudan oluşan anket formu yüz yüze görüşme tekniği ile uygulandı. Katılımcılardan ankete başlamadan önce yazılı onam alındı. Ebeveynlerin yaşları, eğitim durumları, eşler arasında akrabalık bağı, yaşanılan yer, gelir durumu, ailedeki çocuk sayısı, hastanın yaşı, cinsiyetini içeren demografik veriler kaydedildi. Hastaların diyaliz tedavisi durumu, hastalığın süresi, ebeveynlerin aşılar hakkında eğitim alıp almadıkları, ulusal aşılama takviminde olan aşılar ile aşılanma durumu ve ulusal aşı takviminde olmayan meningokok, influenza ve HPV aşıları ile aşılanma durumu kaydedildi. Ulusal aşılama takvimine çocuğun aşılanma zamanından sonra eklenen aşıların tamamlanma durumu ve aşı yaptırmayan ailelere aşı yaptırmama nedenleri soruldu.

Çalışmamıza Hatay Mustafa Kemal Üniversitesi girişimsel olmayan araştırmalar etik kurulundan onay alındı (kayıt no:18/11/2020-27594).

Verilerin istatistiksel analizleri SPSS 21.0 paket programı ile yapıldı. Tanımlayıcı veriler frekans dağılımı ve yüzde olarak sunuldu. Kategorik değişkenler için Pearson ki-kare ve Fisher Exact düzeltmeli ki-kare testleri kullanıldı. Aşılanma oranını etkileyen faktörler arasındaki ilişki Spearman korelasyon analizi ile değerlendirildi, $p<0,05$ için sonuçlar istatistiksel olarak anlamlı kabul edildi.

\section{BULGULAR}

Çalışma sürecince 81 hastanın ebeveynlerine anket uygulandı. Çalışmaya katılan annelerin \%40,7'si ( $n=33$ ) 30-40 yaş arası, babaların ise $\% 45,7$ 'si ( $n=37$ ) 40 yaş üzeriydi. Ebeveynlerin $\% 50,6$ 'sinda akraba evliliği görüldü. Hastaların \%67,9'u ( $n=55)$ şehirde, \%32,1'i ( $n=26$ ) kırsalda yaşamaktaydı. Çalışmaya alınan ebeveynlerin gelir ve eğitim düzeylerinin düşük olduğu görüldü. Ebeveynlerin demografik özellikleri Tablo 1'de gösterilmiştir.

Hastaların \%48,1'i ( $n=39)$ kız, \%51,9'u ( $n=42$ ) erkek ve \%76,5'i 6 yaş ve üzerindeydi. Hastaların \%38,2'si ( $n=31$ ) göçmen ailelerin çocuğuydu. Hastaların KBY tanı yaşı ortanca değeri 6,2 (1-13) yıldı ve \%34,6'sında ( $n=28$ ) hastalık süresi 5 yıldan uzundu. Çalışmaya alınan hastaların primer tanıları değerlendirildiğinde, en sık konjenital böbrek ve üriner kanal anomalisi (CAKUT) $(n=30)$ ve böbrek taşı $(n=12)$ görüldü. Hastaların \%42'si $(n=34)$ diyaliz tedavisi almaktaydı. Hastalarda diyaliz tedavisine başlanma yaşı ortanca değeri 8,4 (2-16) yıldı. Hastaların $\% 16$ 'sı (n=13) immünsüpresif ilaç kullanmaktaydı. Hastaların demografik özellikleri Tablo 2 ve 3'de gösterilmiştir.

Hastalık süresi arttıkça meningokok ve suçiçeği aşılanma oranı da artmıştır (sırasıyla $p=0,003, r=0.34 ; p=0,010, r=0.39$ ). Aylık geliri 2000 TL'den fazla olan hastalarda influenza, meningokok, hepatit A, suçiçeği aşıları ile aşılanma oranları aylık geliri 2000 TL'den az olan hastalara göre istatistiksel olarak anlamlı yüksek saptandı (sırasıyla $p<0,001 ; p<0.001 ; p=0.010 ; 0,029$ ).

Ebeveynlerin \%75,3'ünün ( $n=61$ ) aşı eğitimi aldığı görüldü. Aşı eğitimi alanların \%4,8'i (n=3) sosyal medyadan, \%92,1'i ( $n=58)$ sağlık kuruluşundan, \%3,2'si (n=2) arkadaşlarından aldığı öğrenildi. Aşı eğitimi alan ebeveynlerin çocuklarının ulusal aşı takvimine uygun aşılanma oranı eğitim almayan ebeveynlerin çocuklarına göre istatistiksel olarak anlamlı yüksek saptandı $(p<0,001)$. Hastaların \%85,2'sinin $(n=69)$ ulusal aşı takvimindeki aşılarının tam olduğu görüldü.

Hastaların \%19,8'inin ( $n=16$ ) hepatit B antikor düzeyinin takip edildiği görüldü. Bu oran diyaliz tedavisi alan hastalarda $\% 23,5$ $(n=8)$ olarak saptandı. Ebeveynlere hepatit $B$ antikor düzeyine bakılmama nedeni sorulduğunda \%93,7'si ( $n=60$ ) bilgisinin olmadığını, \%6,3'ü ( $n=4)$ ise ulaşım imkânı olmadığını belirtti. 
Ulusal aşı takvimine hastaların aşılanma zamanlarından sonra eklenen aşılar ve özel aşılar ile aşılanma durumu oldukça düşük saptandı. En sık aşıları yaptırmama nedeni bilgi eksikliğiydi. Aşının yan etkisinden korkan ya da etkinliğine güvenmeyen ebeveyn sayısı düşüktü. Özellikle suçiçeği, hepatit $A$, meningokok, influenza aşılarının maddi imkânsızlık nedeniyle yaptırılamadığı görüldü. En az bilinen ve yaptırılan aşının HPV aşısı olduğu saptandı. Ayrıca HPV aşısını yaptırmama nedeni olarak bir ebeveynin aşının kızlara yapıldığını çocuğu erkek olduğu için yaptırmadığını belirtmesi dikkat çekiciydi. Ebeveynlerin ulusal aşı takvimine sonradan eklenen aşıları ve özel aşıları yaptırma oranı ve yaptırmama nedenleri tablo 4'de gösterilmiştir.

\section{TARTIŞMA}

KBY hastalarında artmış enfeksiyon riski nedeniyle koruyucu sağlık hizmeti olarak aşı uygulamaları son derece önemlidir $(12,13)$.

Aşılanma oranında ailelerin sosyoekonomik durumları önemli rol oynamaktadır. İzmir bölgesinde Üzüm ve ark. (10) yaptı̆ı bir çalışmada ebeveynlerin eğitim durumu ve aylık gelir düzeyi arttkç̧a aşılar hakkında bilgi düzeylerinin artth̆̆, kardeş sayısı arttkça aşıların düzenli yapılmasında azalma olduğu gösterilmiştir. Şanlıurfa bölgesinde Ayçiçek ve ark. (14) da benzer şekilde anne eğitim düzeyi, ailenin gelir durumu ve yerleşim yerinin (kırsal veya şehir) aşılanma oranında etkili olduğunu göstermiştir. Çalışmamızda ebeveyn eğitim düzeyi, gelir durumu ve ailedeki çocuk sayısı ile ulusal aşı takvimindeki aşıları yaptırma oranında anlamlı ilişki saptanmadı. Ancak gelir düzeyi daha yüksek olan hastalarda ulusal aşı takviminde olmayan meningokok ve influenza aşılarının ve ulusal aşı takvimine sonradan eklenen suçiçeği ve hepatit $A$ aşılarının yapılma oranının daha yüksek olduğu görüldü.

Ülkemizde son yıllarda ulusal aşı takvimindeki aşılarla aşılanma oranı \%95'in üzerindedir (15). Çalışmamızda KBY hastalarında bu oran \%85,2 bulundu. KBY hastalarında aşılanma oranının benzer çalışmalara kıyasla düşük bulunmasının nedenleri bu hasta grubunda tekrarlayan hastane yatişları ve immünsüpresif tedaviler sırasında canlı viral aşıların yapılamaması ile ilişkili olabilir. Ancak çalışmamızda aşılanma oranın düşük olmasının nedeni bölge itibarı ile göçmen hastaların oranının fazla olmasıydı. Ebeveynlerin aşılar hakkındaki bilgi düzeyi de aşılanma oranını etkilemektedir. Kars bölgesinde 2019 yılında yapılan annelerin güncel çocukluk aşıları hakkında bilgi durumlarını inceleyen çalışmada annelerin \%77,1'inin aşı eğitimi aldığı görülmüştür (9). Çalışmamızda benzer oranda ebeveynlerin \%75,6'sı aşı eğitimi almıştır. Aşı eğitimi alan ebeveynlerin çocuklarının aşılanma oranının daha yüksek olduğu saptandı. Hastalık süresi arttkça meningokok ve influenza aşılanma oranının da artması yinelenen aşı eğitiminin olumlu etkisini göstermektedir.

Hastaların diyalize girmesi, kan tranfüzyonu gereksinimi olabilmesi ve aşıya bağlı zayıf antikor oluşturmaları hepatit $B$ enfeksiyonu açısından riski arttırmaktadır. Bu yüzden hepatit $B$ aşısının son dozunu takiben 2-3. ay ve sonrasında yıllık olarak antikor takibi önerilmektedir. HBsAb titresi $10 \mathrm{mIU} / \mathrm{ml}$ altında olan hastalara rapel doz yapılmalıdır $(3,16-18)$. Misurac ve ark. (17) periton diyalizi ve hemodiyalize giren 417 hastanın 187'sinde rutin aşılama sonrası hepatit B antikor titresinin koruyucu olmadığını göstermiş ve KBY hastalarında rapel uygulaması ve antikor titre takibinin önemini vurgulamıştır. Çalışmamızda hepatit B antikor düzeyi takip edilen hasta oranının düşük olduğu görüldü. En sık neden ebeveynlerin bu konuda bilgi sahibi olmamasıydı. Diyaliz hastalarında da hepatit $B$ antikor titre takibinin yetersiz olduğu görüldü. Diyaliz tedavisi uygulayan hekimlerin de bu konu da daha dikkatli olmaları ve hastaların hepatit $\mathrm{B}$ antikor düzeyini kontrol etmeleri gerekmektedir. Çalışmamıza katılan hepatit B antikor takibi olmayan hastalarımızın testleri yapıldı ve aşılama gereken hastaların ailelerine bilgi verilerek aşıları yaptırıldı.

Pnömokok enfeksiyonlarına karşı bağışıklamada daha önceleri 2 yaşından sonra uygulanan 23 bileşenli polisakkarit aşı kullanılırken, 2000 yılından sonra immun yanıtı daha etkin olan ve 2. ayda uygulanabilen konjuge pnömokok aşıSı (KPA) kullanımı onay almıştır. Ülkemizde 2008 yılında 7 bileşenli KPA, 2011 yılında ise 13 bileşenli KPA'sı ulusal aşı takvimine eklenmiştir. Varisella enfeksiyonları özellikle böbrek nakli hastalarında önemli bir mortalite nedenidir, bu bakımdan KBY hastalarına mutlaka yapılmalıdır. Hepatit A aşısının yapılması da özellikle böbrek nakli adayları olmak üzere KBY olan çocuklara önerilmektedir $(7,19,20)$. Hepatit A aşısı 2012, suçiçeği aşısı ise 2013 yılında ulusal aşı takviminde yer almıştır. Hastaların aşılanma zamanında sonra ulusal aşı takvimine eklenen bu aşılar sorulduğunda; en az 13 bileşenli KPA'sının tamamlandığı görüldü. Hepatit $A$ ve suçiçeği aşının büyük oranda tamamlanmadığı saptandı. Aşıları yaptırmama nedenleri sorgulandığında ise ebeveynlerin büyük kısmı bilgisi olmadığı için yaptırmadığını belirtti. Suçiçeği ve hepatit A aşısının özel olduğu ve maddi imkânları nedeniyle yaptıramadıklarını belirten ebeveynler de bulunmaktaydı. Ulusal aşı takvimine eklenen aşılar hakkında ebeveynlere bilgi verilmeli ve aşılanmanın takip edilmesi gerekmektedir.

İnfluenza aşısının 6 aydan büyük özellikle kronik hastalığı olan çocuklara her yıl sonbahar aylarında yapılması önerilmektedir. İnfluenza aşısı solunum yolu enfeksiyonlarına bağlı hastanede yatış oranını azaltmaktadır (21). Meningokok enfeksiyonu çocukluk çağında menenjitlerin önemli etkenlerinden biridir ve mortalitesi yüksektir. Meningokok ve influenza aşıları ulusal aşı takviminde bulunmamaktadır. Ancak kronik hastalık raporu olan hastalarda influenza aşısı Sağlık Uygulama Tebliğinin 2.4.3.B maddesine istinaden geri ödeme kapsamındadır. Çalışmamıza katılan hastaların büyük oranda yıllık influenza aşısı ve meningokok aşılarını yaptırmadıkları saptandı. Ebeveynlerin bu aşıları yaptırmama nedenleri sorgulandığında, en sık neden olarak bilgilerinin olmadığını, ikinci olarak da maddi sıkıntıyı belirttiler. Bilindiği gibi HPV enfeksiyonları servikal, vulvavajinal ve penis kanserlerine neden olmaktadır (7). Çalışmamızda HPV aşısının 2 hastada yapılmış olduğu ve bu aşının ebeveynler arasında çok az bilindiği görüldü. Ebeveynlerin HPV aşısını yaptırmama nedeni olarak da en sık bilgi eksikliği ve maddi imkânsızlıklar dikkati çekmekteydi. Dikkat çeken noktalardan biri de HPV aşısının sadece kızlar için önerildiği ve erkeklerde 
önerilmediğinin düşünülmesiydi. Bu nedenlerle aşı eğitiminde HPV aşısının her iki cinsiyette öneminin vurgulanması gerektiğini düşünmekteyiz.

Hocker ve ark. (4) tarafindan 2016 yılında Avrupa'da ülkemizin de yer aldığı çok merkezli, çok uluslu bir çalışmada son dönem böbrek hastalığı olan çocukların nakil öncesi aşı uygulamaları değerlendirilmiştir. Bu çalışmada ülkelerinin aşı takvimine göre 254 hastanın sadece 22'sinde aşıların tam olduğu görülmüştür. Hepatit B $(\% 88,6)$ ve polio $(\% 80,8)$ aşılarındaki yüksek oranlara karşın çalışmamızla benzer şekilde HPV $(\% 27,3)$ aşısı oranının düşük olduğu bildirilmiştir. Erişkin KBY hastalarında aşılanma oranı ve aşılar hakkındaki bilgi düzeyini değerlendiren çalışmalar değerlendirildiğinde aşılanma oranının çocuk hastalardan düşük olduğu görülmüştür. İstanbul'da bir üniversite hastanesinde yapılan tez araştırmasında böbrek nakli yapılan 245 erişkin hastanın aşılanma konusunda bilgi düzeyleri incelenmiştir. Hastaların \%34,3'ünün böbrek nakli öncesi ve sonrası aşılanma hakkında bilgi sahibi olduğu görülmüştür (22). Diyarbakır'da bir eğitim araştırma hastanesinde son dönem böbrek yetersizliği olan 120 hastayı içeren bir başka çalışmada da hastaların aşılanma oranının düşük olduğu bildirilmiştir. Erişkin hastalardaki aşılanma oranlarının düşük olmasının en sık nedeni ise benzer şekilde bu konudaki bilgi eksikliğidir (23).

Çalışmamızda ebeveynlerin çoğunluğunun aşı eğitimi aldığını beyan etmesine rağmen ulusal aşı takvimine sonradan eklenen ve ulusal aşı takviminde olmayan aşılar hakkında bilgilerinin yetersiz olduğu görüldü. Ebeveynlerin düşük sosyoekonomik düzeyde olmaları da bu oranı olumsuz yönde etkilemekteydi. KBY hastalarının aşı eğitiminin yinelenmesi ve aşılanma durumunun takip edilmesi aşılanma oranını arttıracaktır. Aşılanma oranını etkileyen diğer önemli nedenlerden biri de aşı takvimine sonradan eklenen suçiçeği, hepatit $A$ aşılarının ve kronik hastalara ödeme kapsamında olan influenza aşısının ücretli olduğunun düşünülmesidir. Bu aşılarının ücretsiz uygulandığını da vurgulamak gerekmektedir. Aşılama konusunda, KBY hastalarında hepatit B antikor titresinin takip edilmesi, gerekli durumlarda rapel uygulanması açısından hekimlerin farkındalığı ve yinelenen görsel işitsel eğitimlerle ebeveynlerin bilgi düzeyinin arttırılması aşı politikalarının temel hedefleri olmalıdır. Bununla birlikte HPV aşısının her iki cinsiyette önemi vurgulanmalı ve özel aşı takip çizelgesi kullanımı ile aşılanma durumunun takibinin de kolaylaşacağını düşünmekteyiz.

Etik Komite Onayı: Bu çalışma için Hatay Mustafa Kemal Üniversitesi Girişimsel Olmayan Araştırmalar Etik Kurulu'ndan onay alınmıştır (Kayıt no:18/11/2020-27594).

Bilgilendirilmiş Onam: Katılımcılardan bilgilendirilmiş onam alınmıştır.

Hakem Değerlendirmesi: Dış bağımsız.

Yazar Katkıları: Çalışma Konsepti/Tasarım- E.Y., A.T.; Veri Toplama- M.Ç., E.Y.; Veri Analizi/Yorumlama- E.Y., A.T.; Yazı Taslağı- E.Y.; İçeriğin Eleştirel Incelemesi- A.T.; Son Onay ve Sorumluluk- E.Y.

Çıkar Çatışması: Yazarlar çıkar çatışması beyan etmemişlerdir.
Finansal Destek: Yazarlar finansal destek beyan etmemişlerdir.

Ethics Committee Approval: This study was approved by the NonInvasive Researches Ethics Committee of Hatay Mustafa Kemal University (18/11/2020-27594).

Informed Consent: Written consent was obtained from the participants.

Peer Review: Externally peer-reviewed.

Author Contributions: Conception/Design of Study- E.Y., A.T.; Data Acquisition- M.Ç., E.Y.; Data Analysis/Interpretation- E.Y., A.T.; Drafting Manuscript- E.Y.; Critical Revision of Manuscript- A.T.; Final Approval and Accountability- E.Y.

Conflict of Interest: Authors declared no conflict of interest.

Financial Disclosure: Authors declared no financial support.

\section{KAYNAKLAR/REFERENCES}

1. Arısoy ES, Çiftçi E, Hacımustafaoğlu M, Kara A, Kuyucu N, Somer A, et al. Clinical Practical Recommendations for Turkish National Vaccination Schedule for Previously Healthy Children (National Vaccination Schedule) and Vaccines not Included in the Schedule - 2015. Journal of Pediatric Infection 2015;9(1):1-11.

2. Gülcü S, ARSLAN S. Vaccine Application on Children: A Current Review. J DU Health Sci Inst 2018;8(1):34-43.

3. Reddy S, Chitturi C, Yee J. Vaccination in Chronic Kidney Disease. Advances in chronic kidney disease 2019;26(1):72-8.

4. Hocker B, Aguilar M, Schnitzler P, Pape L, Dello Strologo L, Webb NJA, et al. Incomplete vaccination coverage in European children with end-stage kidney disease prior to renal transplantation. Pediatric nephrology 2018;33(2):341-50.

5. Nongnuch A, Ngampongpan $W$, Srichatrapimuk $S$, Wongsa $A$, Thongpraphai S, Boonarkart C, et al. Immune response to influenza vaccination in ESRD patients undergoing hemodialysis vs. hemodiafiltration. PloS one 2020;15(2):e0227719.

6. Bakkaloglu SA, Ozdemir Atikel Y, Paglialonga F, Stefanidis CJ, Askiti V, Vidal E, et al. Vaccination Practices in Pediatric Dialysis Patients Across Europe. A European Pediatric Dialysis Working Group and European Society for Pediatric Nephrology Dialysis Working Group Study. Nephron 2018;138(4):280-6.

7. Fox TG, Nailescu C. Vaccinations in pediatric kidney transplant recipients. Pediatric nephrology 2019;34(4):579-91.

8. Odabaş N, Ayyildiz T. Anne Babaların Çocukluk Dönemi Aşılarına Yönelik Bilgi ve Uygulamalarının Değerlendirilmesi. Medical Journal of Western Black Sea 2020;4(1):7-11.

9. Evran M, Bozkurt HB. Knowledge Status and Affecting Factors about the Current Childhood Vaccines of Mothers of Children Applying to State and University Hospital Pediatric Clinics in Kars. Kafkas Journal of Medical Sciences 2020;10(3):173-9.

10. Üzüm Ö, Eliaçık K, Hortu Örsdemir H, Karadağ Öncel E. Ebeveynlerin Aşı Yaklaşımlarını Etkileyen Faktörler: Bir Eğitim Araştırma Hastanesine Iliş̧kin Değerlendirme. J Pediatr Inf 2019;13:144-9.

11. Stevens PE, Levin A, Bilous WR, Coresh J, Francisco ALM, Jong PE, et al. Kidney Disease: Improving Global Outcomes Chronic Kidney Disease Guideline Development Work Group Members. 2012 clinical practice guideline for the evaluation and management of chronic kidney disease. Kidney Int 2012;3:1-150. 
12. Esposito S, Mastrolia MV, Prada E, Pietrasanta C, Principi N. Vaccine administration in children with chronic kidney disease. Vaccine 2014;32(49):6601-6.

13. Shen AK, Kelman JA, Warnock R, Zhang W, Brereton S, McKean $S$, et al. Beneficiary characteristics and vaccinations in the endstage renal disease Medicare beneficiary population, an analysis of claims data 2006-2015. Vaccine 2017;35(52):7302-8.

14. Ayçicek A. Şanlıurfa kırsal alanında 2-23 aylık çocukların aşılanma hızları. Çocuk Sağlığı ve Hastalıkları Dergisi 2004;47:183-8.

15. Gür E. Aşı kararsızlığı - aşı reddi. Turk Pediatri Ars 2019;54(1):1-2.

16. Vilajeliu A, Sequera VG, Garcia-Basteiro AL, Sicuri E, Aldea M, Velasco $C$, et al. Immunogenicity and immunization costs of adjuvanted versus non-adjuvanted hepatitis $B$ vaccine in chronic kidney disease patients. Human vaccines \& immunotherapeutics 2016;12(9):2317-21.

17. Misurac JM, Vandevoorde RG, Kallash M, lorember FM, Luckritz KE, Rheault MN, et al. Immunogenicity of Augmented Compared With Standard Dose Hepatitis B Vaccine in Pediatric Patients on Dialysis: a Midwest Pediatric Nephrology Consortium Study. Clinical Journal of the American Society of Nephrology 2017;12(5):772-8.
18. Costa N, Canhestro MR, Soares C, Rodrigues JS. Monitoring of post-vaccination anti-HBs titles vaccine in children and adolescents in the pre-dialysis of chronic kidney disease. Jornal brasileiro de nefrologia : 'orgao oficial de Sociedades Brasileira e LatinoAmericana de Nefrologia 2017;39(3):296-304.

19. Neu AM. Immunizations in children with chronic kidney disease. Pediatric nephrology 2012;27(8):1257-63.

20. Banerjee S, Dissanayake PV, Abeyagunawardena AS. Vaccinations in children on immunosuppressive medications for renal disease. Pediatric nephrology 2016;31(9):1437-48.

21. Kara Uzun A. Seasonal influenza vaccination in chronically ill children: the experience of a tertiary healthcare center. Turkish Journal of Pediatric Disease 2020;14:280-5.

22. Ertürk T. Renal Transplantasyon olan Hastaların Aşılanma Konusunda Bilgi, Tutum ve Davranışları. Marmara Üniversitesi Sağlık Bilimleri Enstitüsü. 2017

23. Günay E, Kaya Ş, Yüksel E. The Blind Spot On Hemodialysis: Vaccination. Turkish Bulletin of Hygiene and Experimental Biology 2020;77(2):149-54. 